\title{
European Correspondents Roster Expands
}

The roster of European Correspondents has expanded considerably since its formation and first meeting in Strasbourg, France, November 1987. The network of correspondents was formed to promote the diffusion of information on European materials research activities. [See article in the March $1988 \mathrm{MRS}$ BULLETIN, p. 44.] According to Ian W. Boyd, MRS BULLETIN Associate Editor-Europe, 25 engineers and scientists are currently responsible for collecting and disseminating this information to the international scientific community. They are identified below under the countries they represent. Further nominations have been received from Y. Nissim (France), I. Eisele (West Germany), and D. Rawcliffe (Sweden). The correspondents are planning to keep MRS BULLETIN readers abreast of European materials research activities, said Boyd, by contributing to the BULLETIN's "Up Close" series and reporting on activities of the European Materials Research Society, conferences and other events, professional education opportunities, and scientific breakthroughs. Scientists who want to contribute articles, news items, or information can contact their national correspondents at the addresses listed below.

\section{BELCIUM}

\section{Luc Baufay}

Project Manager

Grand Hornu

Rue Sainte Louise

7320 Boussu, Belgium

Telephone 32 (65) 373427

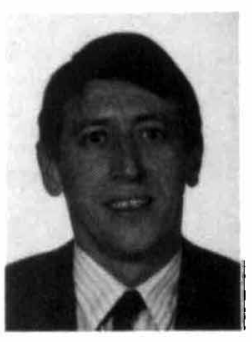

Luc Baufay received a BS in physics and a PhD in solid state physics from Mons University, BeIgium. His thesis dealt with the synthesis of semiconducting compounds by laser irradiation of metallic, sandwich-like films. He received an MRS Student Award in 1983 and he joined IBM, San Jose, and AT\&T Bell Laboratories as a postdoctoral fellow. His research included materials processing by laser irradiation such as laser oxidation, LCVD, and localized metallization by laser-induced decomposition of solid compounds. He is currently project manager at Label S.A. (Laser Applications Belgium) and is responsible for the applications based on interactions between laser beams and materials. His main project involves laser processing in microelectronics. He is also teaching optoelectronics at the University of Liege.

\section{I.V. Mitchell}

Commission of the

European Communities

Directorate General

for Science, Research

and Development

DG XII C/4 (SDME 2/15)

200, Rue de la Loi

B-1049 Brussels, Belgium

Telephone (32) 22357649

Telex COMEU B 21877

Fax (32) 22362007

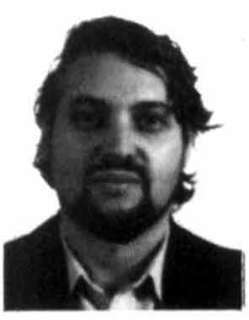

I.V. Mitchell, educated at the Universities of London and Keele, has a BSc and PhD in physics. In 1971, he was awarded a CNRS research scholarship which he spent at the Nuclear Research Centre in Strasbourg, France. He later took a postdoctoral fellowship at the Department of Materials Science at Oxford. Since 1974. Mitchell has been with the Commission of European Communities in Belgium. Up to 1983, he was in charge of a materials surface analysis group at the Central Bureau for $\mathrm{Nu}$ clear Measurements, Geel, where newly developed high energy nuclear techniques were applied to surface studies. More recently he moved to the Brussels headquarters to be scientific project manager in charge of several new materials research programs supported by the EEC. Mitchell is author of more than 50 scientific publications and is editor of two books, one on high performance magnetic materials and one on European research on materials substitution.

\section{GREECE}

Stathis D. Peteves

Commission of the

European Communities

joint Research Center

P.O. Box 2

1755 ZG Petten,

The Netherlands

Telephone (02246) 5656

Telex 57211 REACP

Fax (31)0 2246-1002

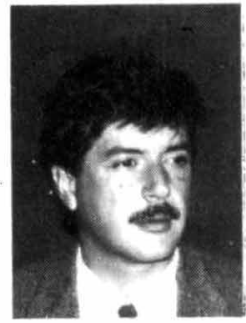

Stathis D. Peteves received a BS in metallurgical engineering from the National Technical University, Athens; an MS in materials engineering from George Washington University, Washington, DC; and a PhD in materials science from the University of Florida in 1986. Since 1987 he has been a research staff member of the Institute of Advanced Materials of the Commission of the European Communities at Petten. He is presently leading the advanced ceramics joining and machining projects. His research interests include ceramic-metal interfaces, surface modification of ceramics, ceramic composites, and crystal growth kinetics. Peteves has written 10 papers in these areas is an active member of MRS, E-MRS, TMS, ASM, $A C S$, and $A A C G$.

\section{FRANCE}

Eric Fogarassy

Centre de Rechenches Nucleaires

Laboratorie PHASE

23 Rue du Loess,

B.P. 20

Strasbourg Cedex 67037

France

Telephone 88286657

Telex 890032F CRO

Fex 88280990

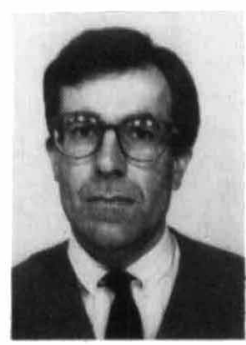

Eric Fogarassy received his doctorate in materials science in 1975 from the University of Paris VI. He joined Philips Laboratories for two years and served as an assistant professor in solid state physics at the University of Tunis (Munisia). In 1978 he joined the Centre National de la Recherche Scientifique as a member of the Semiconductor Division (PHASE) of the Centre de Recherches Nucleaires, Strasbourg, where he worked on laser doping for solar cell applications. Fogarassy spent one year at the Solid State Division of Oak Ridge National Laboratory (Tennessee, USA) working in different fields of semiconductor laser processing with pulsed eximer lasers. Since 1985 he has been leader of the Laser Photochemistry Group for Electronic Device Applications, PHASE Laboratory.

\section{A. Golanski \\ CNET - Grenoble \\ BP-98 \\ F-38243 Meylan, France \\ Telephone 76514067 \\ Telex 980727 \\ CNET GRENO \\ Fax 76903443}

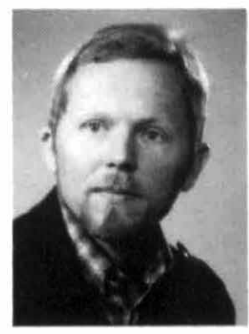

A. Golanski was educated in Poland. During 1976/77 he was a postdoctoral fellow at McMaster University, Ontario, Canada. In 1978 he joined the Centre National d'Etudes des Telecommunications, Grenoble, where he is presently working as a Physics and Technology Division head adviser. His principal interests are in ion beam modification of materials, thin film reactions and analysis. His work has covered ion-implantation-induced damage in $\mathrm{Si}$, recoil implantation from thin $\mathrm{SiO}_{2}$ films on $\mathrm{Si}$, creation cynamics and annealing mechanisms of ion-implantation-induced paramagnetic defects in amoxphous $\mathrm{SiO}_{2}$, buried $\mathrm{SiO}_{2}$ layer formation by coxygen implantation, and structural properties of thin silicide films. He has been coorganizer and/or co-editor of the E-MRS conferences on Induced Defects in Insulators (1984), Dielectric Layers in Semiconductors (1986), and Beam and Plasma Enhanced Processing (1987). 


\section{IRELAND}

Gabriel M. Crean

National Microelectronics

Research Centre-Cork

Lee Maltings

Proppect Row

Cork, Ireland

Telephone 010253

21276871 , Ext. 2721

Telex UK 265871

Fax 270271

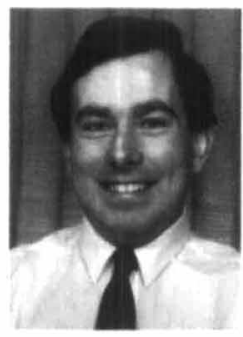

Gabriel M. Crean graduated in electrical engineering from the Dublin Institute of Technology in 1983. He was awarded a French government scholarship and studied at the Institut National Polytechnique de Grenoble, receiving an MSc in optoelectronics in 1984. From 1984 to 1987 he held a scholarship at the Centre National d'Etudes des Telecommunications Microelectronics Research Centre, Meylan, France. He received a PhD in Physics from the Universite Scientifique Technologique et Medicale de Grenoble (USTMG) in 1987 for work on the nondestructive characterization of the mechanical properties of very thin film interconnection layers via surface acoustic wave analysis. His postdoctoral work in the Electrical Engineering Department at University College London during 1987 concerned the development of air-coupled noncontact acoustic profilometry systems and the characterization of ion implantation damage using novel thermal wave techniques. In January 1988, he joined the research staff of the National Microelectronics Research Centre, Cork, Ireland.

\section{Alan Moore}

Microelectronics \&

Electrical Engineering

University of Dublin

Trinity College

Dublin 2, Ireland

Telephone 01772941 , Ext. 1432

Secretary, Ext. 1738/9

Telex 25492 TCD EI

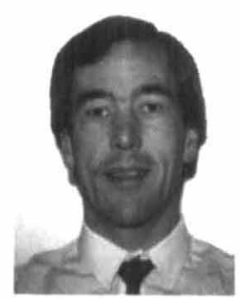

Alan Moore is a senior lecturer in the Department of Microelectronics and Electrical Engineering, Trinity College Dublin, where he is responsible for teaching integrated circuit technology. He recelved his BSc (Eng) in 1974 and his PhD (Fabrication of Microwave Devices) in 1978, both from Queen's University Belfast. His current research interests include studies of the material properties of amorphous silicon and spin-on glasses for use as planarizing layers in integrated circuit fabrication.
ITALY

Salvatore Campisano

Dipartimento di Fisica

Universita di Catania

Corso Italia 57

95100 Catania, Italy

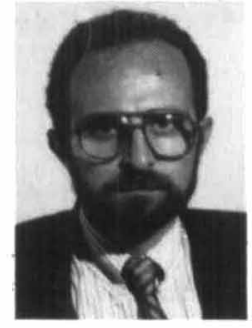

Salvatore Campisano is full professor of solid state physics at the University of Catania. He obtained a physics degree in 1969 and started research in ion beam analysis and ion implantation. He has been active in reseanch areas such as thin films metallurgy, laser annealing of semiconductors, ion-beam-induced phase transitions, and has authored more than 110 scientific papers and two book chapters on these subjects. He has been co-organizer and proceedings co-editor of the 1986 International Conference on Ion Beam Modification of Materials and has been involved in the organization of other smaller international meetings. A reseanch fellow at Caltech in 1974 and consulting scientist at AT\&T Bell Laboratories in 1983 , Campisano is now in charge of the CNRGNSM committee for supporting semiconductor research in Italy.

Pietro Cavallotti

Dipartimento Chimica

Fisica Applicata

Politechnico di Milano

Piazza Leonardo

da Vinci 32

20133 Milano, Italy

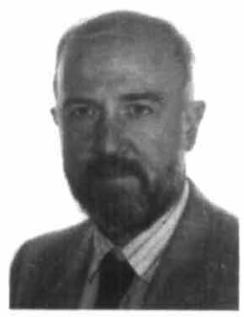

Pietro Cavallotti is full professor of metals scence at Milano Politecrico (since 1985), where he had taken a degree in chemical engineering (1963) and is in charge of the course on metallurgical chemistry for chemical, mechanical, and nuclear engineers. Cavallotti is president of the Nonferrous Metals Center of the Italian Metallurgy Association, and a member of European commissions for powder metallurgy and electrochemistry. He is author of about $100 \mathrm{pa}$ pers and reviews concerning metallurgical physical chemistry, magnetic materials production and properties, structure of metal electrodeposits, hot corrosion powder properties, and metallungy.

Lucio Zanotti

MASPEC - CNR

Via Chiavari 18/A

43100 Parma, Italy

Telephone (0521) $96841 / 2 / 3$

Telex 531639 MASPECI

Fax (0521) 96315

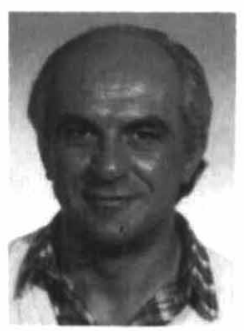

Lucio Zanotti is director of the MASPEC Institute of the CNR, Parma, Italy. He was born in
1944 and recetved his degree in chemistry from Bologna University in 1969. Since 1970 he has been working at MASPEC Institute, where he started research in semiconducting compounds and has headed the technology department promoting research in material preparation from the melt and vapor; crystal growth of binary, ternary, and multinary compounds; high pressure synthesis technology; and impurity and compositional inhomogeneity analysil. Zanotti has written about 80 papers and reviews and holds patents in these areas.

\section{THE NETHERLANDS}

Jan Dieleman

Philips Research Labs

P.O. Box 80.000

5600 JA Eindhoven,

The Netheriands

Telephone 3140791111

Telex 35000 phtc nl -

Telex routing nlwevd Fax 3140743783

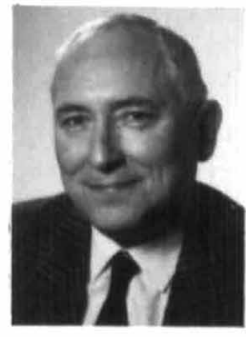

Jan Dieleman joined Philipe Research Laborntories, Eindhoven, Netherlands, in 1959 to study the structure of centers and their relation to luminescence, semiconductivity, and photoconductivity of solids. In 1962 he obtained a PhD in physical chemistry from the Free University, Amsterdam. Since 1964 he has headed research departments studying II-VI compounds, photoconductors, solid state ionic conductors, infrared imaging, TV pickup tube targets, solar cells, plasma chemistry, technology for compuct fluorescent lamps. At present he is head of the Surface Science Department, where the program is aimed at studying mechanisms of processes for growth, etching or modification of surfaces and thin films.

Mathias P.A. Viegers

Philips Research Labs P.O. Box 80000

5600 JA Eindhoven,

The Netheriands

Telephone 3140791111

Telex 35000 PIITC NL

Fax 3140743783

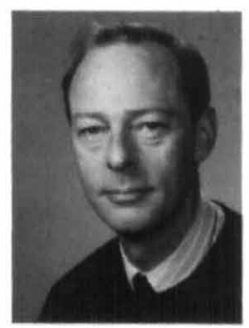

Mathias P.A. Viegers received his BS and MS degrees in physical chemistry from the Catholic University of Nimeguen. In 1976 he obtained the PhD degree in science from the same university, presenting a thesis on Mössbauer spectroscopy of gold in molecular crystals and small particles. Viegers then joined Philips Reseanch Laboratories, where his research activities included EXAFS studies of amorphous metal alloys using synchrotron radiation, and the design of an in-house EXAFS facility. With TEM he studied electroceramic materials (including the new ceramic superconductors) and procese-induced structures in semiconductor materials. He was the author and co-author of several publications in each of these fields. His 
research interests broadly cover materials assessment and focus on the atomic structure of interfaces. Viegers is vice chairman of the Dutch Vacuum Society and member of the editorial board of the Dutch Joumal of Physics.

\section{PORTUGAL}

João.L. Baptista

Department of Ceramics

Engineering

University of Aveiro

Aveiro, Portugal

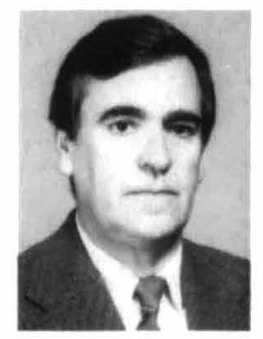

João Lopes Baptista is professor at the Department of Ceramics Engineering. University of Aveiro, Portugal. He graduated in chemistry from the University of Lisbon in 1964 and obtained a $\mathrm{PhD}$ in chemistry from the University of Manchester, England in 1968. Prior to joining the University of Aveiro, his research activities involved the field of solid state chemistry. He joined the University's Ceramics Engineering Department in 1975 when it was established, supervising the development of curricula and research areas. Baptista's research interests are in electronic ceramics (ZnO-based varistors, grain boundary barrier layer capacitors, gas sensors), high strength ceramics for medium and high temperature applications $\left(\mathrm{Si}_{3} \mathrm{~N}_{\omega} \mathrm{SiC}\right.$, whisker and short fiber reinforced composites), and high reactivity ceramic powder preparation.

Jose C. Soares

Universidade de Lisboa

Centro de Fisica Nuclear

Av. Prof. Gama Pinto 2

1699 Lisboa, Codex

Portugal

Telephone 773325 ;

$773911 ; 774297$

Telex 62593 IIFM P

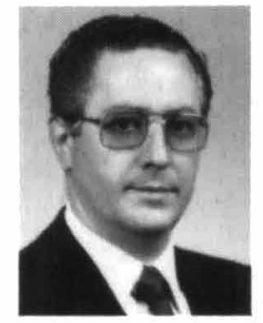

Jose Carvalho Soares studied physics in the University of Lisbon and obtained the Doktor Der Naturwissenschaften degree in 1975 at the University of Bonn, working in the group of Professor Bodenstedt. Since 1976 he has been on the faculty of science, University of Lisbon, and is now associate professor. Soares works in the Department of Physics and in the Nuclear Physics Research Center. He is the leader of the Nuclear Solid State Physics Group which introduced the perturbed angular correlation technique to measure hyperfine fields at radioactive nuclei introduced by ion implantation in different types of materials. In collaboration with the Department of Physics of the National Laboratory (LNETI) he introduced RBS/channeling and NRA techniques to the group's activities. $\mathrm{He}$ is responsible for collaboration projects funded by INICT and INIC (Portugal), GTZ and Volkswagenwerk Foundation, the British Council, French and Spanish cultural agreements, and CERN using the ISOLDE Facility.

He has been a Von Humboldt fellow in Germany and visited U.S. laboratories through a NATO and a Fulbright fellowship. In 1987 he organized the NATO School on "Nuclear Physics Applications on Materials Science." Since 1984 he has been an MRS member and E-MRS national delegate.

SPAIN

Betty M. León-Fong Universidade de Santiago Escola Tecnica Superior de Enxeneiros

de Telecomunicacion Vigo, Spain

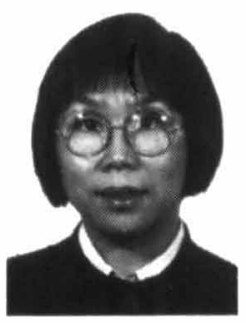

Betty M. León-Fong was awarded a Diplom Physiker by the Technical University of $\mathrm{Aa}$ chen, West Germany, where she has been scientific collaborator at the Institute of Semiconductor Technology working on CVD of AIN thin films. She later received her PhD from the Universidad Complutense of Madrid, for work on liquid crystal blue phases. At present she is Professor Titular of Applied Physics at the Telecommunications Engineering School of the University of Santiago in Vigo, where her main activities since 1984 have been in the laser processing of materials.

\section{SWEDEN}

\section{Hasse Fredriksson \\ Royal Institute of}

Technology

Department of Casting

of Metals

P.O. Box S-100

44 Stockholm, Sweden

Telephone 4687906000

Telex 10389 KTHBS

Fax 468109199

Hasse Fredriksson (born in 1939) is a professor in the Department of Casting of Metals, Royal Institute of Technology, Stockholm. He received his PhD in 1971 at the Department of Physical Metallurgy. He is doing research in the field of solidification of metals, and he is especially interested in solidification phenomena under microgravity and also at high cooling rates. He is also working on simulation of the structures formed in different casting processes.

\section{Stefan Nygren}

Royal Institute of

Technology

Microwave Department

Box 70033

S-100 44 Stockholm

Sweden

Telephone

Nat. - 08238320 ;

Int. - 468238320

Telex 12875 INMIC S
Stefan Nygren received the MSc from the University of Uppsala, Sweden, in 1983. He subsequently did research and teaching at the University of Uppsala and at the Royal Institute of Technology, where he is presently employed. In 1985 he received the licentiate degree in solid state electronics from the Royal Institute of Technology. His research interests are in the field of VLSI metallization, where he has made contributions concerning diffusion barriers and MOS gate electrodes. During 1986 and 1987 he spent 14 months at CNET, Grenoble, where he worked on new gate configurations.

\section{SWITZERLAND}

Ginther Harbeke

RCA Laboratories Ltd.

Badenerstrasse 569

8048 Zurich, Switzerland

Telephone (01) 4926350

Telex 822373

Fax (01) 4910007

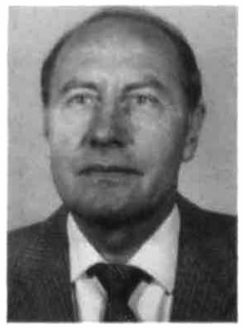

Since 1961 Gïnther Harbeke has been with the RCA Laboratories, which recently associated with the Paul-Scherrer-Institute. He also holds a lecturing assignment as honorary professor at the University of Cologne, West Germany. Harbeke's reseanch involves the optical spectroscopy of solids, particularly semiconductors. This includes the study of the electronic band structure and exciton effects of elemental and compound semiconductors, layer and quantum well structures. His work also deals with localized and intrinsic lattice vibrations, structural phase transitions in ferroelectric and other materials studied by elastic light scattering and infrared absorption.

Hans Erich Hintermann, Director

Centre Suisse d'Electronique

et de Microtechnique SA

Maladiere 71

Case Postale 41

CH-2007 Neuchatel, Switzerland

Telephone 038240161

Telex 952664 CSEM

Fax 038254078

Hans Erich Hintermann, Dr sc nat ETH, is director of the Materials and Micromechanics Division, Centre Suisse d'Electronique et de Microtechnique SA. He graduated in physics and chemistry from the Swiss Federal Insttute of Technology, Zurich and has held various research and management positions with the Laboratoire Suisse de Recherches Horlogeres (LSRH), Neuchatel and a research position at the C.F. Norberg Reseanch Center of Electric Storage Battery, Inc., Yardley, Pennsylvania. After the merger of LSRH and Centre Suisse d'Electronique et de Microtechnique SA, Hinterman became director and head of the Materials and Micromechanics Division. He is a 
member of the OECD Group on Wear of Industrial Materials; the editorial board of Wear, Tribology Intermational, Surface Technology, Oberfiäche-Surface, Reviews of Powder Metallurgy, and the Elsevier tribology series; the International Institution for Production Engineering Research, CIRP; and the advisory board of the U.S. DOEECUT Tribology Program.

Peter C. Oelhafen Institute of Physics University of Basel Basel CH-4056,

Switzerland

Telephone (61) 442040

or (61) 442080

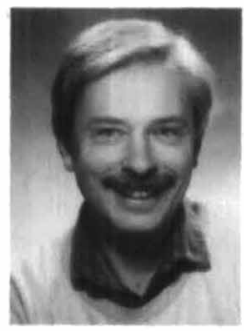

Peter C. Oelhafen, is a docent in physics at the University of Basel, Institute of Physics. He wrote his PhD thesis at the Eidgenössische Technische Hochschule, Zurich, on photoelectron spectroscopy of liquid metals and in 1978 joined the Institute of Physics in Basel. He received the Max Auwärter Award in 1980. In 1982 and 1982 Oelhafen worked at the IBM T.J. Watson Research Center at Yorktown Heights, New York, in the field of metal-semiconductor interfaces. His present research concerns the electronic structure of amorphous alloys, amorphous thin films, interface properties, ion beam-solid interactions and surface properties of liquid alloys.

\section{WEST GERMANY}

Dannie Jost

Max Planck Institut

fuir Quantenoptik

Garching bei Munchen

West Germany

Dannie Jost received a BS degree in chemistry from California State University, Northridge, MS in theoretical chemistry from California State University, Los Angeles, and PhD in physics from the University of Berne, Switzerland. She is now with the Max-Planck-Institute for quantum optics in Garching, near Munich, pursuing her interests in the interaction of short laser pulses with condensed matter, with special emphasis on the dynamics of energy transfer.

\section{UNITED KINGDOM}

Ian W. Boyd

Department of Electronic and Electrical

Engineering

University College London

Torrington Place

London WC1E 7JE,

United Kingdom

Telephone 01-387 7050, ext. 3956

Telex 296273 UCLENG.G Fax 01-387 4350

Ian W. Boyd is a member of the academic staff of the Electronic Engineering at University College London. He received BSc (with first class honors) and $\mathrm{PhD}$ degrees in applied physics in 1979 and 1982 from Heriot-Watt University, Scotland. From 1982-1984, he was a research scientist at the Center for Applied Quantum Electronics, at North Texas State University. His principal interests are in laser beam interactions with semiconductors. He has worked on rapid thermal processing, silicon axidation, laser induced chemical and surface reactions, and the fundamentals and applications of picosecond laser pulses with semiconductors. Boyd is author of a book, Laser Processing of Thin Films and Microstructures, and has co-published over 50 technical papers. He is a member of the EMRS Board of Delegates and Associate EditorEurope of the MRS BULLETIN. He co-chaired the E-MRS symposium on Photon, Beam, and Plasma-Assisted Processing at the meeting held May 31-June 2.

Stuart J.C. Irvine

Royal Signals and Radar

Establishment

St. Andrews Road

Malvern

Worcester WR14 3PS,

United Kingdom

Telephone 068452733 , ext. 2715

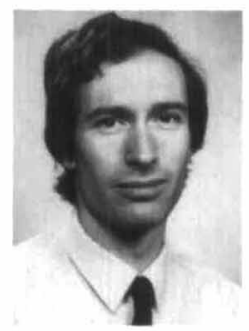

Stuart J.C. Irvine is currently employed at the Royal Signals and Radar Establishment (RSRE), Malvern, leading a small team of materials scientists looking at new epitaxial growth technologies for infrared detectors. He received his BSc in physics from Loughborough University in 1974 and $\mathrm{PhD}$ in physical metallurgy and science of materials at Birmingham University in 1978. His thesis was on the absorption of hydrogen in intermetallics, a potentially important energy storage medium. Before joining RSRE in 1978, he carried out research into de Haas-van Alphen measurements on praseodymium which led to the first fermi surface determination of a double hexagonal rare-earth crystal. Irvine's research interests at RSRE have involved vapor phase epitaxial growth of II-VI semiconductors and here resulted in pioneering techniques for growth of cadmium mercury telluride using metal-organic vapor phase epitaxy (MOVPE) and ultraviolet photo-epitaxy. This research has led to the publication of over
40 papers and two patents. He is treasurer to the British Association for Crystal Growth and a member of the Institute of Physics.

Karen J. Reeson

Department of Electronic and Electrical Engineering

University of Surrey

Guildford

Surrey GU25XH,

United Kingdom

Telephone (0483) 571281

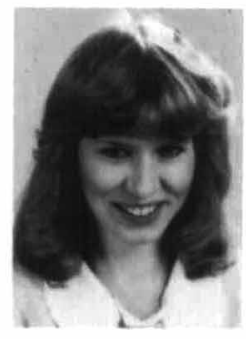

Karen J. Reeson graduated from Leicester University in 1981 with a BSc in chemistry and geochemistry. Between 1981 and 1984 she conducted her PhD research on the optical properties of ore minerals at the British Museum (Natural History) and City of London Polytechnic. In 1984 she joined the Solid State Devices and Ion Beams Technology Group at the Department of Electronic and Electrical Engineering, University of Surrey as a research fellow. Her research interests include the study of compound synthesis using energetic ion beams and ion beam analysis.

John O. Williams

Department of Chemistry

University of Manchester

Institute of Science

and Technology

P.O. Box 88

Manchester M60 1QD

United Kingdom

Telephone 612363311

Telex 66609

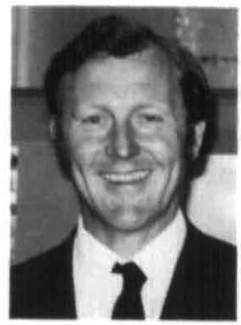

John Owen Williams received his BSc, PhD and DSc from the University of Wales. Following a period at Aberystwyth, he was appointed to a chair in chemistry at UMIST (Manchester) in January 1984 and presently heads a Solid State Chemistry Group and is chairman of the Centre for Electronic Materials there. He is a past chairman of the Applied Solid State Chemistry Group (Royal Society of Chemistry) and is presently a member of the SERC's Molecular Electronics Committee. Williams' research interests are in the field of solid state chemistry and over the past 20 years these have covered aspects of molecular solids and inorganic semiconductors. His most recent attention has focused on molecular thin films and currently there is considerable activity within his research group on LB films. These are prepared from novel, synthesized molecular systems involving porphyrins and phthalocyanines containing various metal centers and metal-metal bonds. Work on inorganic semiconductors also focuses on the preparation and characterization of thin films. Compatibility between molecular and inorganic thin films is being investigated. A recent development within the group has been the study of electronic ceramic materials induding lead lanthanum zirconium titanate (PLZT) and the bronzes. 